\title{
Colorectal cancer: A total provincial experience with survival analysis
}

\author{
B.H. WEINERMAN, MD, FRCPC, K.B. ORR, BSC, MSC. PHD
}

\begin{abstract}
A review of 1212 cases of colorectal cancer from the Manitoba Tumour Registry from 1974 through 1976 was done in order to establish survival rates for a total population, to examine the role of tumour differentiation and stage of disease on survival, and to examine the incidence of disease in the rural and urban populations. Stage was the most important factor in determining survival although the difference between stages $C_{1}$ and $C_{2}$ disease was not significant. However, a continuing relapse rate was seen in all patients with any type of infiltrating disease $\left(\mathrm{B}_{1}\right.$ and $\left.\mathrm{B}_{2}\right)$. There appeared to be continuing relapse patterns in all those groups to at least 96 months. Histology was also an independent predictor of survival even when controlling for stage of disease. Some patients with well differentiated colorectal cancers with stage D disease (over $10 \%$ ) were alive at 42 months. Age was not found to be a significant factor in survival except for those individuals over 71-years-old and sex was not an important factor. There was increased incidence of colorectal cancer in urban as opposed to rural populations, suggesting that possible differences in lifestyle may play a role in causation. Can J Gastroenterol 1989;3(3):126-130
\end{abstract}

\section{Key Words: Colorectal cancer}

Department of Internal Medicine, St Boniface General Hospital; and the Manitoba Cancer Treatment and Research Foundation, Winnipeg, Manitoba

Correspondence and reprints: Dr B.H. Weinerman, Head, Department of Medicine, St Boniface

General Hospital, 409 Taché Avenue, Winnipeg, Manitoba R2H 2 A6

Received for publication September 16, 1988. Accepted March 13, 1989
O OLORECTAL CARCINOMA IS ONE OF the most commonly occurring neoplasms in Canada with 9000 new cases and 5130 deaths in 1979 (1). In view of the many screening studies which are now being done for this disease ( 2 ) and the trials of adjuvant therapy which have been reported (3-6), the authors decided to review the total provincial experience in Manitoba to establish certain baselines in order to guide future studies. Several questions were asked in this study: what are the survival rates of colorectal cancer in the total provincial experience and what are the patterns of relapse; does the differentiation of the tumours as reported on the routine pathology records bear prognostic significance; what is the influence of staging on survival; is there a difference in the incidence of the disease in the rural and urban populations which might be a reflection of diet or 


\section{Le cancer colorectal: Expérience portant sur une province en-} tière et analyse de survie

RESUME: Une étude portant sur 1212 cas de cancer colorectal tirès du Manitoba Tumour Registry de 1974 à 1976 a été effectuée pour établir le taux de survie d'une population totale; pour examiner le rôle de la différenciation des tumeurs et du stade de la maladie sur la survie; et pour déterminer également l'incidence de la maladie en populations rurales et urbaines. Le stade d'évolution de la maladie était la facteur de survie le plus déterminant bien que la différence entre les stades $C_{1}$ et $C_{2}$ de la maladie ne soit pas significative. Ce qui est surprenant, par contre, c'est l'index de récidives répétées chez tous les patients souffrant de maladie infiltrante, quel qu'en soit le type $\left(B_{1}\right.$ et $\left.B_{2}\right)$. Il semble y avoir des séquences de récidives continuelles dans tous ces groupes jusqu à environ 96 mois. Néanmoins, l'histologie permet également de prédire indépendamment la survie même quand le contrôle porte sur le stade de la maladie. Certains cas de cancer colorectal bien différenciés au stade $\mathrm{D}$ de la maladie (plus de $10 \%$ ) étaient en vie à 42 mois. Lâge ne semble pas significatif excepté pour les individus de plus de 71 ans et le sexe n'est pas un facteur important. L'incidence du cancer colorectal est plus élevée en milieu urbain, ce qui laisse entendre que le mode de vie joue peut-être un rôle.

other factors; and is there an influence of age or sex on survival?

\section{METHODS}

The Manitoba Tumour Registry is an organization to which all biopsies in the province are reported by law. The authors reviewived all cases of colorectal cancer reported to the registry in a three year period (1974 to 1976) and extracted the following information: age of patients; sex; rural or urban address; therapy (surgery - abdominal, perineal, hemicolectomy, etc); postoperative treatment (radiotherapy, chemotherapy, no treatment); the presence of venous or lymphatic invasion exclusive of known lymph node involvement; differentiation of the tumours as noted by the pathology report; stage of disease by the Astler Coller classification (7) (Table 1); site of the cancer; initial diagnosis; and last

\section{TABLE 1}

Stage of disease by the Astler Coller classification

Dukes A Confined to mucosa and submucosa

Dukes $B_{1}$ Through muscularis, not through serosa, negative nodes

Dukes $B_{2}$ To or through serosa or into pericolic fat, negative nodes

Dukes $C_{1} \quad$ Not through serosa, positive nodes Duke's $\mathrm{C}_{2}$ Through serosa, positive nodes Dukes D Distant metastases

Large bowel distal to peritoneal reflection does not have serosal count follow-up or death. Deaths from carcinoma were listed as deaths, but deaths from other intercurrent illness were treated as censored information in the lifetable analysis plots. If secondary malignance intervened, survival was again calculated up to that time and subsequently censored unless it was clear that death was due to the colon cancer.

Survival rates were determined by the actuarial life-table method (8) and were compared using the Wilcoxan or log-rank statistic (8). To identify the parameters that predict survival, multivariate regression analysis was also carried out. The explanatory variables included histology and stage of disease.

\section{RESULTS}

A total of 1212 cases were reviewed. There were 603 males and 609 females. There were 807 cases from urban areas and 405 from rural parts of Manitoba. The population of Manitoba, 1986 census, was $1,071,232$ with 664,551 from urban areas. The ratio of urban cancers to the total urban population was 0.0012 and the ratio of rural cancers to the total rural population was 0.00093 . The difference between those ratios was significant ( $\mathrm{P}=0.0002)$. The population of Manitoba under the age of 60 years was also studied because older individuals may have moved into the city on retirement and then developed their cancer, thereby inflating the urban numbers.
There were 169 cases of cancer in a population of 511,920 (population under 60) in urban areas and 98 cases out of a population of 367,808 in rural areas (significant difference $\mathrm{P}=0.05$ ). There were 813 cases where Astler Coller staging could be ascertained from chart review (Table 2). Figure 1 displays the life-table survival plots of the groups according to stage. Actuarial mean survival for each stage was as follows: $A, 93$ months; $B_{1}$, 66 months; $B_{2}, 48$ months; $C_{1}, 18$ months; $\mathrm{C}_{2}, 20$ months; and $\mathrm{D}$, six months. There was a significant difference in survival plots for stages $A$ versus $B_{1}(P=0.001)$, $B_{1}$ versus $B_{2}(P=0.01), B_{1}$ versus $C_{1}$ $(\mathrm{P}=0.001), \mathrm{B}_{2}$ versus $\mathrm{C}_{1}$ or $\mathrm{C}_{2}(\mathrm{P}=0.01)$ and $C_{2}$ versus $D(P=0.001)$. There was no significant difference between $C_{1}$ versus $\mathrm{C}_{2}$.

\section{TABLE 2}

Astler Coller stages of colorectal cancer at presentation

\begin{tabular}{cr}
\hline Stage & Number (\%) \\
\hline$A$ & $31(3.9 \%)$ \\
$B_{1}$ & $92(11.7 \%)$ \\
$B_{2}$ & $233(29.7 \%)$ \\
$C_{1}$ & $19(2.4 \%)$ \\
$C_{2}$ & $232(29.7 \%)$ \\
$D$ & $206(26.4 \%)$ \\
\hline
\end{tabular}

There was a continuing relapse pattern seen in all stages of disease. The death rate per year in stage $B_{1}$ was approximately $5 \%$ per year until year 4 when it increased to $10 \%$ and maintained, at that rate, with the last death at nineand-one-half years. The same analysis for $B_{2}$ revealed a death rate of $15 \%$ for the first year and $20 \%$ per year thereafter with the last death at nine-and-onehalf years and for $\mathrm{C}_{2}$ the death rate was $30 \%$ yearly for six years and that rate continued to eight years.

Four hundred and forty-five cases could be identified by histologic type and stage. Cancers, if classified in a mixed grade, were analyzed with the poorer prognostic group. Poorly differentiated and anaplastic cancers were analyzed together. Three basic groups were identified: well differentiated, moderately differentiated and poorly differentiated (Table 3). Table 4 lists correlation between histologic grade and stage. Patients with 
well differentiated tumours did not enjoy a better survival than those with moderately differentiated, but both had a better survival than those with poorly differentiated tumours $(\mathrm{P}=0.001)$ (Figure 2). When comparing the $C_{2}$ and $D$ stages in the well differentiated and poorly differentiated groups there was a significant survival difference in favour of the well differentiated group $(\mathrm{P}=0.05$ and $\mathrm{P}=0.04$, respectively) (Figure 3 ). There was also a significant difference in the moderately differentiated $\mathrm{C}$, and the poorly differentiated $\mathrm{C}_{2}(\mathrm{P}=0.05)$. Significance was not reached with the other stages.

\section{TABLE 3}

Histologic grade of colorectal cancer

\begin{tabular}{lr}
\hline $\begin{array}{l}\text { Histologic } \\
\text { classification }\end{array}$ & $\begin{array}{c}\text { Number of } \\
\text { cases }(\%)\end{array}$ \\
\hline Well differentiated & $129(29.2 \%)$ \\
Moderately differentiated & $233(52.8 \%)$ \\
Poorly/anaplastic & $83(18.8 \%)$ \\
\hline
\end{tabular}

Stage of disease and differentiation (well differentiated) were confirmed by Cox multiple regression analysis as independent prognostic variables with stage being the most important. Age of patients was also analyzed in terms of percentage, stage and survival. Age and stage of patients at presentation are listed in Table 5. Total survivals were compared along each of the age groups. No difference was found between the survival patterns with the exception of the group older than 71 years at diagnosis who had a significantly shorter survival time, with a large number dying within the first six months. Mean survival times were as follows: younger than 37 years, 23 months; 40 to 51 years, 23 months; 51 to 60 years, 17 months; 61 to 70 years, 23 months; and older than 71 years, six months (Figure 4). Sex of the patient appeared to have no influence on survival. Some patients were given chemotherapy at the oncologists discretion for node positive disease. The authors identified 21 stage $\mathrm{C}$ patients with node positive disease and compared their survival with the rest of the $\mathrm{C}$ group. The median survival of the chemotherapy ( 5 -fluorouracil) group was
TABLE 4

Correlation between histologic grade and stage

\begin{tabular}{cccr}
\hline Stages & Well differentiated & Moderately differentiated & Poorly differentiated \\
\hline$A$ & $9(7.0 \%)$ & $0(0 \%)$ & $1(1.2 \%)$ \\
$B_{1}$ & $32(24.8 \%)$ & $34(14.6 \%)$ & $4(4.8 \%)$ \\
$B_{2}$ & $40(31.0 \%)$ & $98(42.1 \%)$ & $12(14.5 \%)$ \\
$C_{1}$ & $2(1.6 \%)$ & $7(3.0 \%)$ & $5(6.0 \%)$ \\
$C_{2}$ & $28(21.7 \%)$ & $67(28.7 \%)$ & $32(38.6 \%)$ \\
$D$ & $18(14.0 \%)$ & $27(11.6 \%)$ & $29(34.9 \%)$ \\
$A+B$ & $(31.8 \%)$ & $(14.6 \%)$ & $(6.0 \%)$ \\
$A, B, B_{2}{ }^{*}$ & $(62.8 \%)$ & $(56.6 \%)$ & $(20.5 \%)$ \\
\hline
\end{tabular}

- No nodal metastases

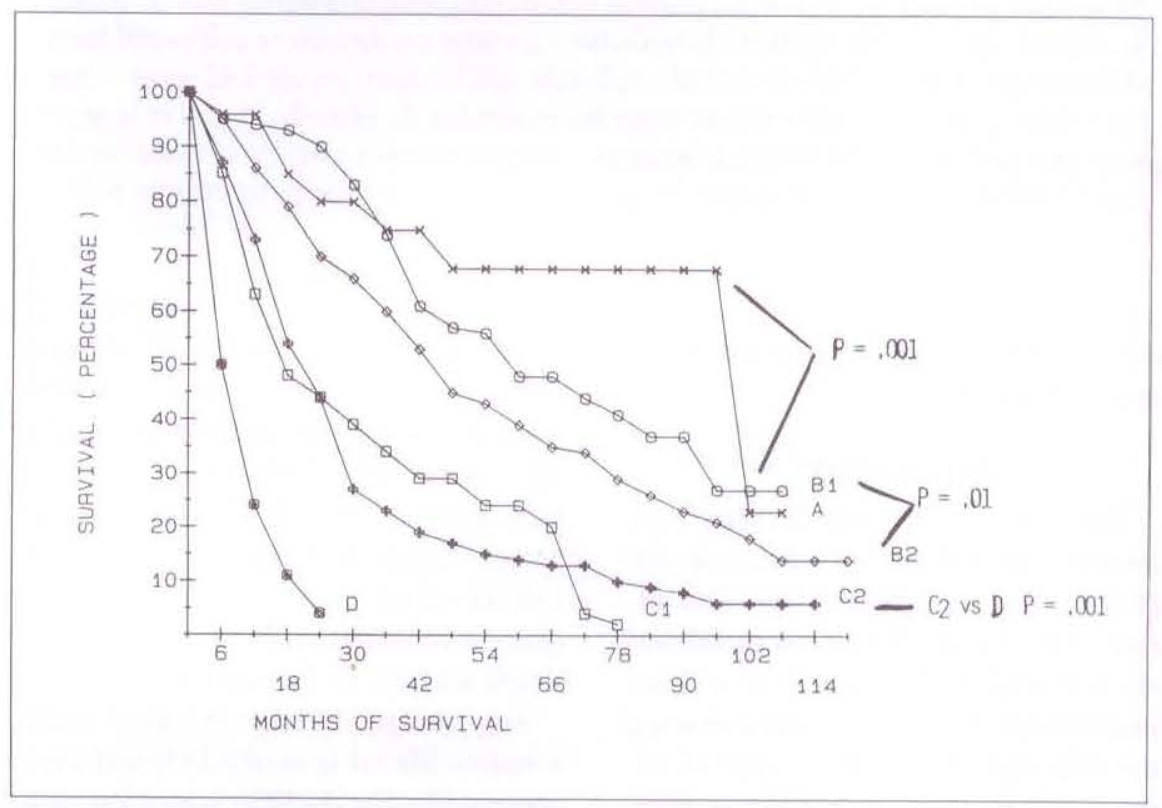

Figure 1) Survival by disease stage

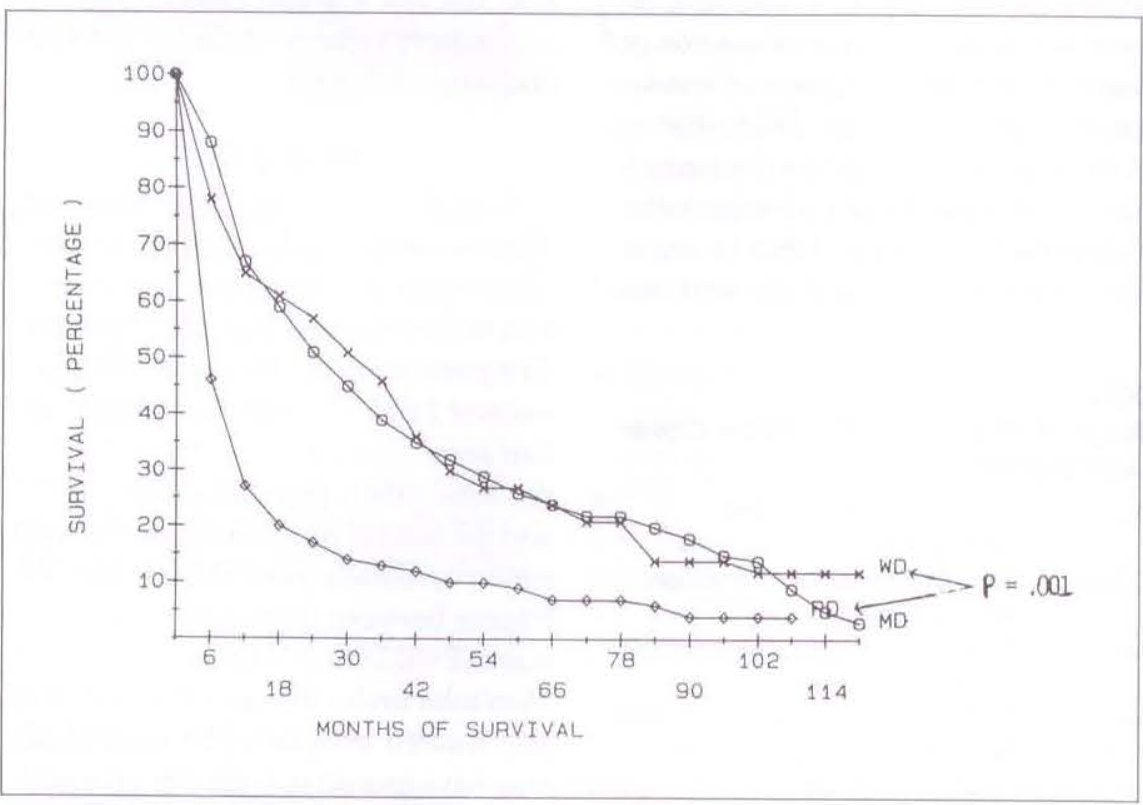

Figure 2) Survival by histology. PD Poorly differentiated; WD Well differentiated; MD Moderately differentiated 
TABLE 5

Age and stage of patients at presentation

\begin{tabular}{lcccc}
\hline Age (years) & $\begin{array}{c}\text { Percentage } \\
\text { of group }\end{array}$ & $\begin{array}{c}\mathrm{A}, \mathrm{B}_{\mathrm{B}} \mathrm{B}_{2} \\
\text { percentage }\end{array}$ & $\begin{array}{c}\text { Stages } \\
{\mathrm{C}, \mathrm{C}_{2}, \mathrm{D}}^{2} \\
\text { percentage }\end{array}$ & $\begin{array}{c}\mathrm{D} \\
\text { percentage }\end{array}$ \\
\hline 37 or younger & 1.6 & 20 & 80 & 6.7 \\
38 to 50 & 7.5 & 55 & 45 & 16.9 \\
51 to 60 & 15.6 & 46.2 & 53.8 & 20.7 \\
61 to 70 & 28.1 & 53.6 & 46.4 & 19.5 \\
71 or older & 47.1 & 50.9 & 49.1 & 22.5 \\
\hline
\end{tabular}

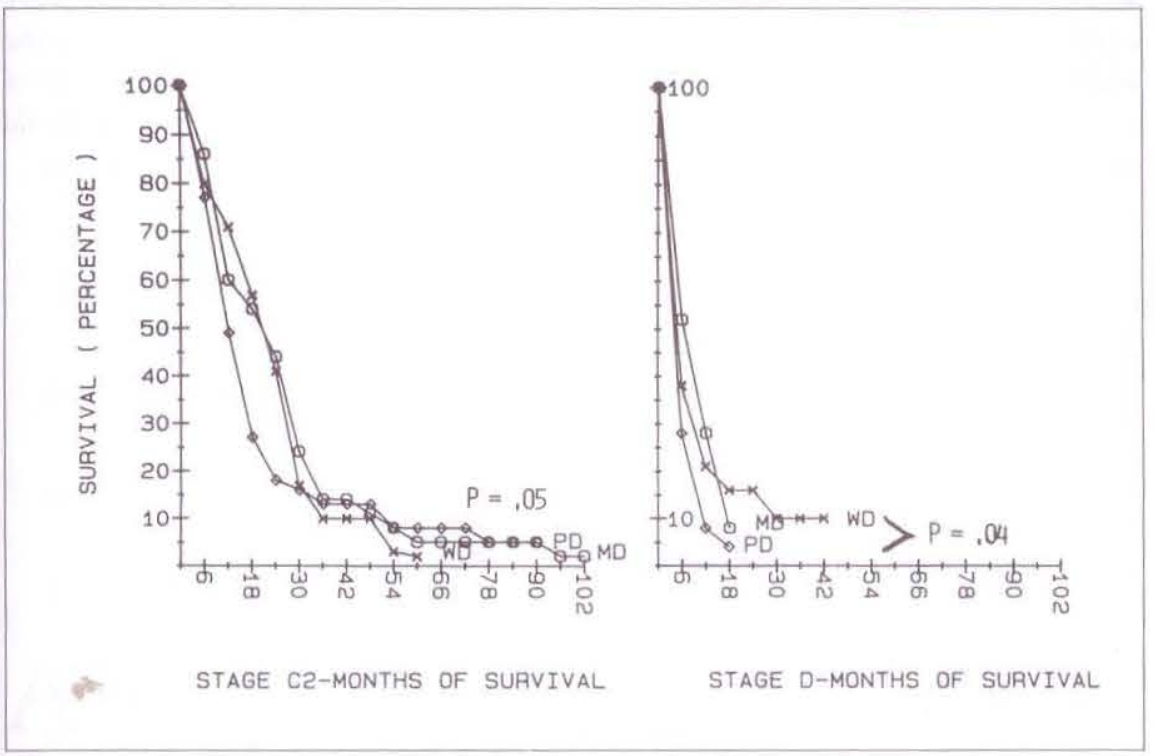

Figure 3) Survival of patients with $\mathrm{C}_{2}$ or D disease. PD Poorly differentiated; WD Well differentiated; MD Moderately differentiated

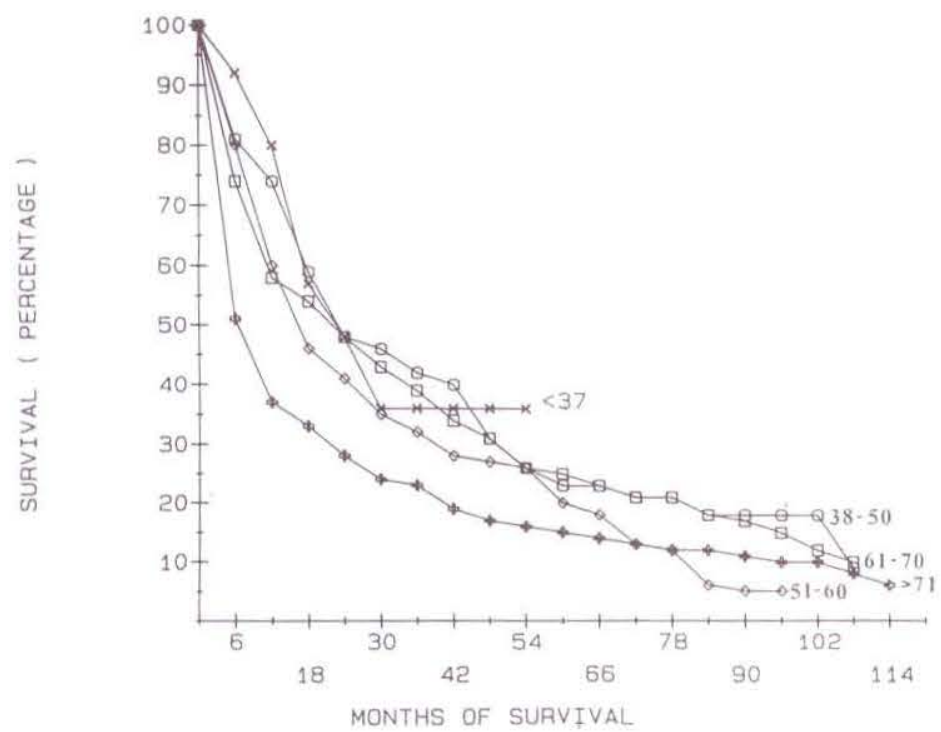

Figure 4) Survival by age at diagnosis. No significant difference except for patients older than 71 years
15 months compared to 22 months for the rest of the group (significantly different at $\mathrm{P}=0.05$ ).

\section{CONCLUSIONS}

A total of 1212 cases of colorectal cancer in the province of Manitoba were reviewed (all cases from 1974 to 1976) with a mean follow-up of nine years. The most important factor in survival was stage of disease. However, it is very significant, especially when interpreting screening studies in the future, that even early disease ( $A$ and $B$ stage) had a continued relapse pattern.

Although this is a retrospective study and many patients reported with $A$ or $B$ stage disease may have had more advanced disease because of inaccurate staging, the authors did take care to try to ensure from the records the accuracy of the staging. This pattern of relapse would then be analogous to breast cancer (9). This has not always been seen by others (10-11) and flattening of the survival curves around 10 years may be seen. The death rates from recurrences varied with the different stages.

The most significant factor in survival in colorectal cancer appears to be stage. Some interrelationship exists between stage and differentiation of the tumours as indicated in Table 4. There was a significant difference in survival when comparing stages $\mathrm{C}$, and $\mathrm{D}$ of the well differentiated and the poorly differentiated groups, indicating the importance of tumour differentiation even expressed crudely in a provincial retrospective study. In fact, $10 \%$ of the well differentiated group with stage $\mathrm{D}$ at presentation survived over three years without intervening treatment.

The independence of stage and histology was confirmed by multivariate regression analysis. These facts must be borne in mind when comparing surgical resection studies with 'normal survival patterns'. The well differentiated group more frequently presented with isolated metastases and some had a prolonged survival even without surgical intervention. It might be speculated that the well differentiated group is the type of histologic grade represented in surgical resection of metastases. Since a proportion of these individuals will obvious- 
ly survive years without surgical intervention to remove metastases, it underlines the need for carefully controlled studies of all such interventions.

The continued relapse pattern seen in early stage disease calls careful attention to screening studies and claims of cure based on the theory of orderly progression. Screening studies should incorporate tumour differentiation to analyze whether the more poorly differentiated groups subsequently show up with metastases.

Sex and age had no effect on survival. The youngest age group could not be adequately examined due to the small

\section{REFERENCES}

1. Statistics Canada. Cancer in Canada. Toronto, Ontario, May 1983.

2. Simon JB, Occult blood screening for colorectal carcinoma: A critical review. Gastroenterology 1985;88:820-37.

3. Gastrointestinal Tumor Study Group. Adjuvant therapy of colon cancer Results of a propsectively randomized trial. N Engl J Med 1984; 310:737-43.

4. Gastrointestinal Tumor Study Group. Prolongattion of the disease-free interval in surgically treated rectal carcinoma. N Engl J Med number of patients. Individuals older than 71 years at diagnosis may have a poorer survival, but factors other than cancer may have contributed to these results. Of some interest in this study is the higher than expected incidence of colorectal cancer in the urban areas compared to rural areas. This was still significant, although at a lower level, when the authors attempted to correct for people moving to the city upon retirement and then developing their cancer. Rural or urban cancers were identified by the address of the patient at diagnosis. By reanalyzing data for people under the age of 60 the authors hope to have at

1985;312:1465-72.

5. Higgins GA, Amadeo JH, McElhinney J, et al. Efficacy of prolonged intermittent therapy with combined 5-Fluorouracil and Methyl-CCNU following resection for carcinoma of the large bowel. Cancer 1984:53:1-8.

6. Boulis-Wassif S, Gerard A, Loygue J, et al. Final results of a randomized trial on the treatment of rectal cancer with preoperative radiotherapy alone or in combination with 5-Fluorouracil, followed by radical surgery. Cancer 1984;53:1811-8

7. Astler VB, Coller FA. The prognostic least partially corrected for population movement. Since the greatest incidence of disease is in the older population, it cannot be entirely ruled out that older groups retired and moved to urban areas before their tumours were discovered.

There was apparently no benefit of adjuvant 5-fluorouracil in this retrospective study and the drug may have been detrimental. However, the reasons physicians chose to treat particular patients clearly may have biased the authors sample. Randomized trials have to be done to see the effect of adjuvant therapy but in view of this result, a no treatment control would seem to be an important trial design.

significance of direct extension of carcinoma of the colon and rectum. Ann Surg 1954:139:846-51.

8. Coldman AJ, Elwood JM. Examining survival data. Can Med Assoc J 1979; 121:1065-71.

9. Henderson IC, Canellow GP. Cancer of the breast. N Engl J Med 1980;302:17-90.

10. Wright $\mathrm{CH}$. Cancer of the colon and rectum: 30 year follow-up study. Can J Surg 1985;28:311-4.

11. Jass JR, Love SB, Northover JMA. A new prognostic classification of rectal cancer. Lancet 1987;i:1303-6. 


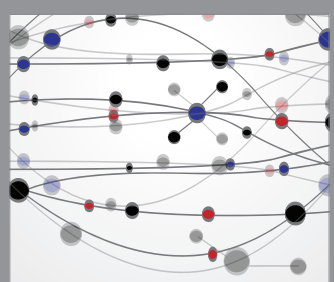

The Scientific World Journal
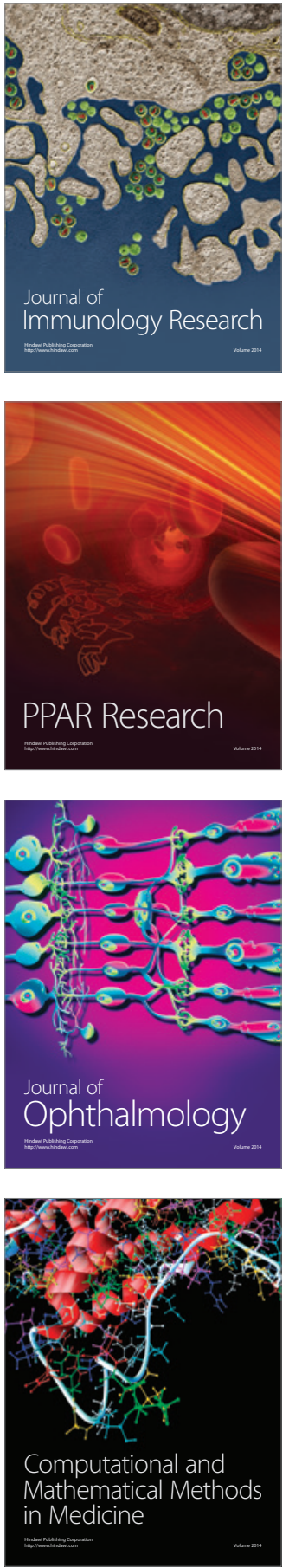

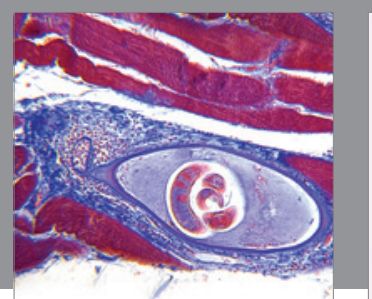

Gastroenterology Research and Practice

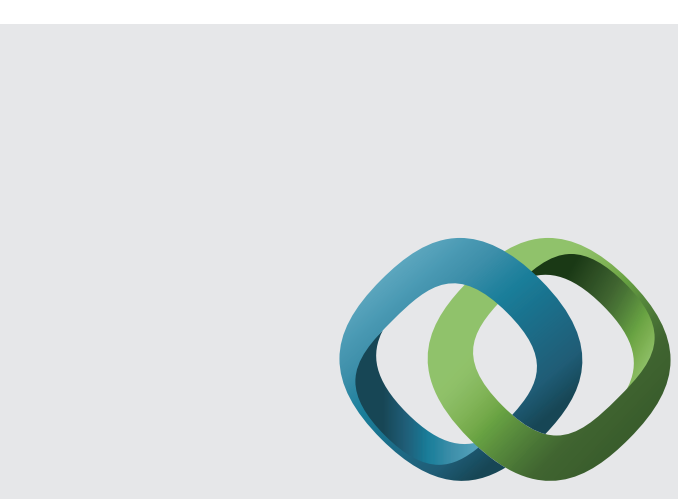

\section{Hindawi}

Submit your manuscripts at

http://www.hindawi.com
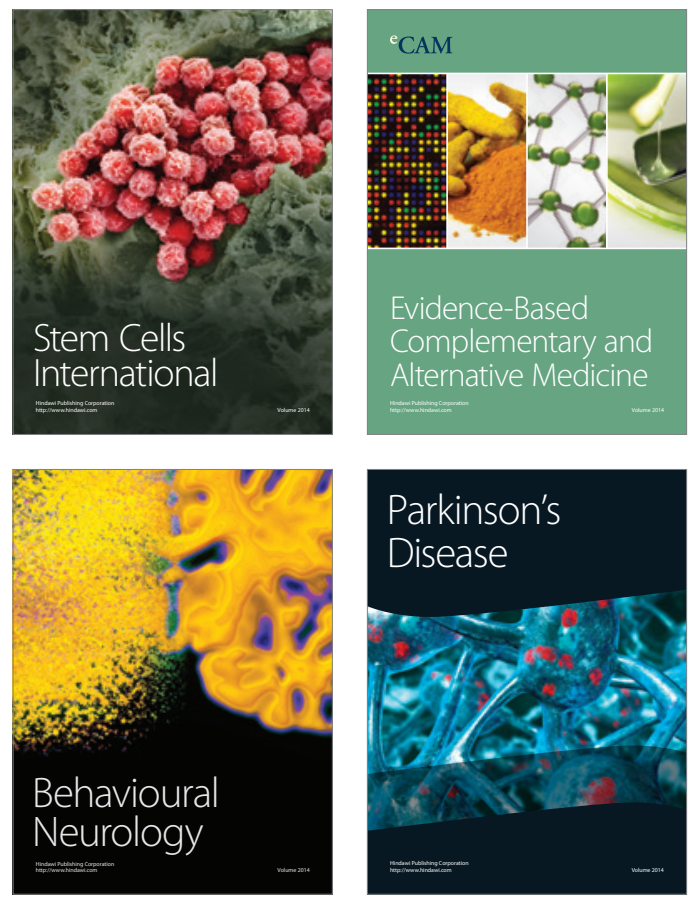
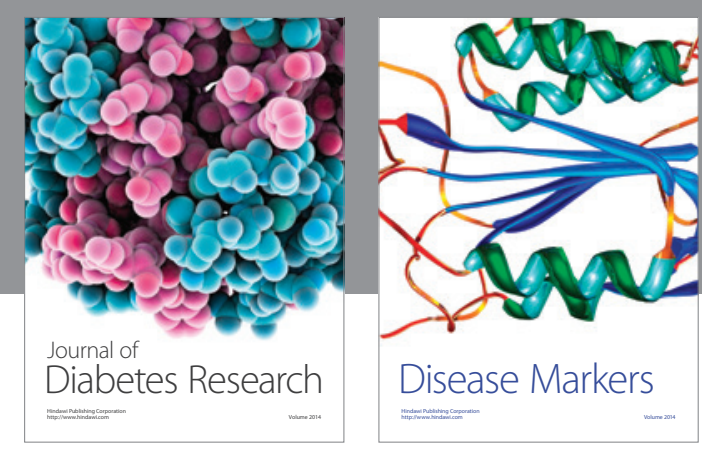

Disease Markers
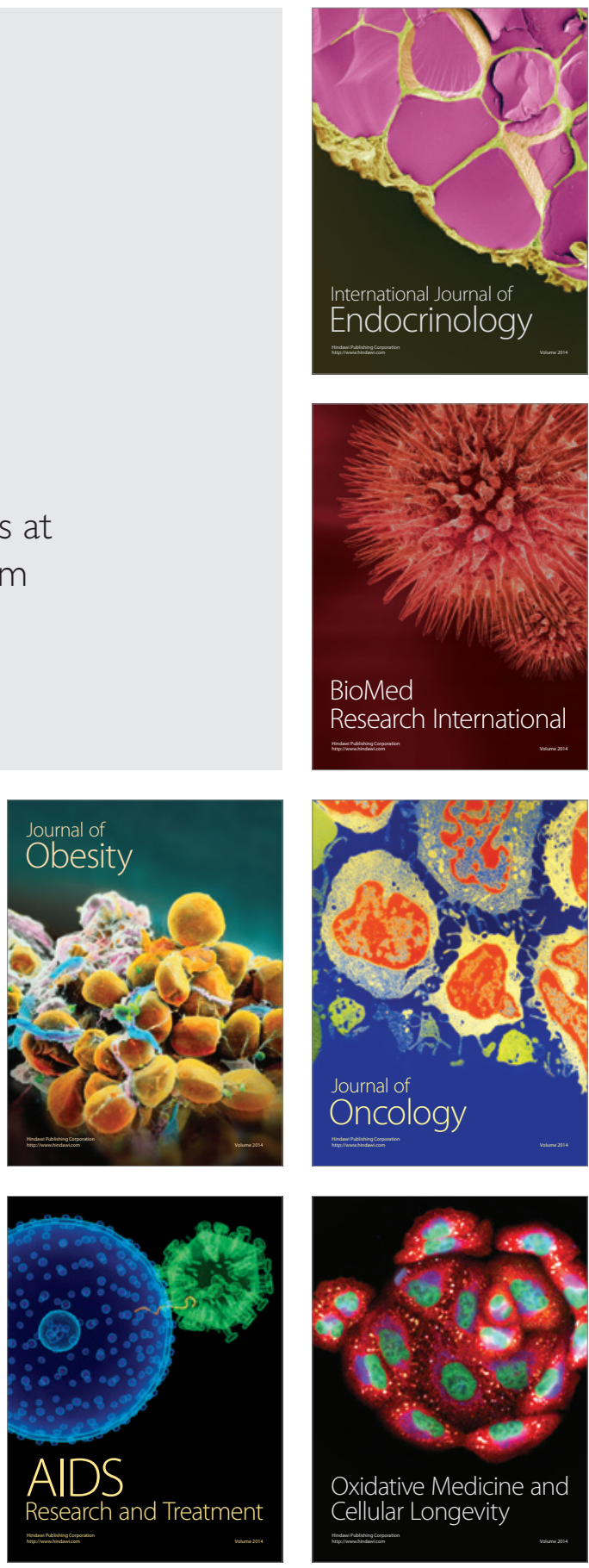